International Journal of Biological Research, 2 (1) (2013) 6-8
International Journal of Biological Research
Journal home page: $\begin{gathered}\text { www.sciencepubco.com/index.php/IJBR } \\ \text { doi: } 10.14419 / \text { ijbr.v2il.1417 } \\ \text { Research Paper }\end{gathered}$

\title{
Effect of combined oral contraceptive (Duofem) on platelet indices in female wistar rats
}

\author{
Toryila J.E. ${ }^{1 *}$, Amadi K. ${ }^{2}$, Odeh S.A. ${ }^{2}$, Egesie U.G. ${ }^{2}$ Adelaiye A.B. ${ }^{1}$, Mohammed A. ${ }^{1}$, Achie L.N. ${ }^{1}$, Atsukwei D. ${ }^{3}$ \\ ${ }^{1}$ Human Physiology Department, Ahmadu Bello University, Zaria \\ ${ }^{2}$ Human Physiology Department, University of Jos, Jos \\ ${ }^{3}$ Human Physiology Department, Bingham University, Kālu \\ *Corresponding author E-mail: joetoryila@gmail.com
}

\begin{abstract}
This research is aimed at determining the effect of low dose combined oral contraceptive (Duofem) on platelet count and mean platelet volume.

Methods: 80 female wistar rats weighing 180 to $250 \mathrm{~g}$ were used for the study. They were divided into four groups of 20 rats each (each group containing 10 treated and 10 control rats). The treated rat received $0.66 \mathrm{mg} / \mathrm{kg}$ body weight of combined oral contraceptive intragastrically, for 36, 48, 60 and 72 days in five-day cycles (four-day treatment with one-day break). Rats in control groups remain a standard chow and water. Platelet count and mean platelet volume were determined using Symex Kx21-N Haematology auto analyzer.

Results: There were no significant difference in platelet count and MPV in all the treated groups compare to the control $(\mathrm{P}<0.05)$.

Conclusion: Low dose ethinylestradiol in combined oral contraceptive (Duofem) produces no changes in platelet count and mean platelet volume.
\end{abstract}

Keywords: Combine oral contraceptive, platelet count, mean platelet volume (MPV).

\section{Introduction}

Birth control is a major factor in public health and welfare, preserving the general and reproductive health of women and allowing them to choose the moment of a planned pregnancy. Combined oral contraceptives (COCs) are the most widely used hormonal contraceptives and also the most popular non-surgical method of contraception (Odlind et al, 2002).

Many epidemiological studies have addressed the potential thrombosis has been demonstrated (Jack et al, 1995). More recently, studies suggested that the risk of venoms thrombeombolism was higher with the third generation COCs progestogens (desgestral and gestodene) (WHO, 1995).

Although combined oral contraceptives (COCs) are highly efficacious and have good safety profile, the estrogen and the progression are known to exert some adverse influence on some haematology and haemostatic parameters (Pepitrial Group, 1995).

Platelets are derived from fragmentation of precursor megakaryocytes in the bone marrow. The play a fundamental role in haemostasis and are a natural source of growth factors (Bernd et al, 1999). Platelet size, measured as mean platelet volume (MPV) is associated with platelet reactivity (Bulur et al, 2012).

Platelet size measure as means platelet volume (MPV) is a marker of platelet function (David, 1996). Increase platelet reactivity shortened bleeding time (BT) and increase platelet aggregation (Martin et al, 1990). The biological significance of platelet volume and its relationship to bleeding time (BT), platelet thromboxane B2 production and megakaryocyte nuclear DNA concentration has been demonstrated (Ankara et al, 1996). The large platelet home higher5 thrombotic potential than small platelets (Karpatkin et al, 1978).
The estrogen component of $\mathrm{COC}$ has been shown to increase platelet aggregation and to enhance clot formation (Inmam et al, 1970). Platelets are integral components of occlusive thrombi that result in myocardial infractions and ischemic stroke; they may also contribute to the development and progression of more chronic atherosclerotic lessons that underlie these acute events (Ruggeri, 2001). MPV is increase in acute myocardial infarction and has been identified as independent risk factors for future myocardial infrastructure and stroke (Brackken et al, 2010).

Previous studies conducted in female rats and in women, COCs were found to induce platelet hyperactivity that was related to oxidative stress (Babatunde et al, 2004). Large platelets are more reactive produce more prothrombotic factors and aggregate more easily. Platelet size can be readily estimated using automated analysers, (Malley et al, 1995). It is generally accepted that platelet volume and density are determined at thrombopoiesis and that, once in the circulation, platelets do not change in size. It is suggested that both MPV and platelet count are under independent hormonal control (Martin et al, 1983, Martin, 1989).

The investigation is aimed at determined whether or not the COC has any effects a platelet count and mean platelet volume.

\section{Materials and methods}

\subsection{Animals}

Eighty (80) female wistar rats aged $10-12$ weeks weighing 180 $250 \mathrm{~g}$ were used for the study. The animals were obtained at the Animal House of Human Physiology Department, Ahmadu Bello University Zaria. They were divided into four groups of 20 rats each comprising 10 treated and 10 control rats. They were placed 
in stainless steel cages (5 rats each). The rats were fed with normal rat chew (vital feels grand cereal oil mills, Jos) and allowed with hard labour.

The treated group (10 rats) received COC (DUOFEM) $0.66 \mathrm{mg} / \mathrm{kg}$ body weight ingrastically for 36, 48, 60 and 72 days in 5 days cycles (4 days treatment with a 1 day break). Experimental animals in this study were treated in accordance with the National Protection Laws of Animal Welfare.

\subsection{Drugs}

The COC drug used in this study is Duofem tablets $(0.03 \mathrm{mg}$ ethinylestradiol and $0.3 \mathrm{mg}$ norgestral). Manufactured by pifer, Belgium packed and market by society for family health Nigeria. Other reagents and chemicals used were of analytical grade and of the purest quality available commercially.

\subsection{Blood sample collection}

Animals were an anesthetized with acetone prior to blood withdrawal. $2 \mathrm{ml}$ of blood sample was collected by cardiac puncture into EDTA bottles. Platelet count and mean platelet volume (MPV) were analyzed by a trained medical laboratory scientist in Haematology Department ABUTH Zaria using symex K x 21 - N Haematology auto analyzer.

\subsection{Statistical analysis}

All data were presented as mean \pm standard error of mean. Student t-t-test was used to analyze the data SPSS version 19 software (SPSS Inc. Chicago, USA). Statistical significance was based on P vale $<0.05$.

Group however, there were no statistical significant changes in mean platelet count in both groups and their controls (Table 2)

\subsection{Results}

There was decreased in mean platelet count in all the groups compared to the control .There was also no statistical significant decreased in mean platelet volume in group 1 (36 days), group 2 (48 days) and group 4 (72 days). However, there was a significant decreased in MPV in group 3 (60 days) $(\mathrm{P}<0.03)$.

Table 1: Effect of combined oral contraceptive platelet count and mean platelet volume

\begin{tabular}{llll}
\multicolumn{3}{l}{ platelet volume } & \\
\hline Duration & Group & PLT $\left(\right.$ X 10 $\left.0^{9 / \mathrm{L}}\right)$ & MPV \\
\hline 36 days & 1 & $626.25 \pm 42.92$ & $6.90 \pm 0.28$ \\
& Control & $805.25 \pm 21.36$ & $6.52 \pm 0.06$ \\
48 days & 2 & $547.50 \pm 23.80$ & $6.57 \pm 0.02$ \\
& Control & $618.50 \pm 94.70$ & $6.50 \pm 0.14$ \\
60 days & 3 & $462.75 \pm 14.89$ & $6.47 \pm 0.12$ \\
& Control & $668.00 \pm 27.52$ & $5.90 \pm 0.11$ \\
72 days & 4 & $670.00 \pm 22.99$ & $7.97 \pm 0.08$ \\
& Control & $668.25 \pm 28.27$ & $7.77 \pm 0.20$ \\
\hline
\end{tabular}

Table 2: Effect of combined oral contraceptive on platelet count in rat

\begin{tabular}{lllll}
\hline Duration & Expt. Group & Control & $\mathrm{P}-$ value & \\
\hline 36 days & $626.25 \pm 42.29$ & $805.25 \pm 21.36$ & 0.26 & $\mathrm{NS}$ \\
48 days & $547.50 \pm 23.80$ & $618.50 \pm 94.70$ & 0.24 & $\mathrm{NS}$ \\
60 days & $462.75 \pm 14.89$ & $668.00 \pm 27.52$ & 0.23 & $\mathrm{NS}$ \\
72 days & $670.00 \pm 22.99$ & $668.25 \pm 28.27$ & 0.98 & $\mathrm{NS}$ \\
\hline \multicolumn{5}{c}{ NS - Not significance. S - Significance. Significance at P $<0.05$}
\end{tabular}

Table 3: Effect combined oral contraceptive on mean platelet volume in

\begin{tabular}{lllll} 
rats. & & & \\
\hline Duration & Expt. Group & Control & $\mathrm{P}-$ value & \\
\hline 36 days & $6.90 \pm 0.28$ & $6.52 \pm 0.06$ & 0.35 & $\mathrm{NS}$ \\
48 days & $6.57 \pm 0.01$ & $6.50 \pm 0.14$ & 0.78 & $\mathrm{NS}$ \\
60 days & $6.47 \pm 0.12$ & $5.90 \pm 0.11$ & 0.03 & $\mathrm{~S}$ \\
72 days & $7.77 \pm 0.20$ & $7.97 \pm 0.08$ & 0.53 & $\mathrm{NS}$ \\
\hline \multicolumn{4}{c}{ NS - Not significance. $\mathrm{S}$ - Significance. Significance at P < 0.05}
\end{tabular}

NS - Not significance. S - Significance. Significance at $\mathrm{P}<0.05$.

\section{Discussion}

Combined oral contraceptives are the most widely used hormonal contraceptives. More recent studies suggest that the risk of various thromboembolisms was higher with the third generation combined oral contraceptive.

There was decreased in mean platelet count in all the groups treated with COC compared to their controls. However there was no statistical significant decreased in mean platelet count in all the groups treated in COC. This result is contrary to the findings of Saijda et al, 2006) who found significant increase in mean platelet in subjects treated with oral contraceptives. This could be as a result of the variation in the concentration of estrogen present in the combined oral contraceptives.

This result is also contrary to that of Jack et al in Lagos were they reported an increased in mean platelet count in the subjects treated with COC. This result however, was in agreement with the finding of Bulur et al, 2012, where they reported no significant evidence in platelet count in users of COC. The result also agreed with that of Peter (2011) who found no statistical significant in platelet count in women on COC not less than six months. Abdalla et al, 2008, also found no significant changes in platelet count in Sudanese women.

There were also no statistical significant changes in MPV in group 1, 2 and 4 treated with COC compared to the control. There was however significant decreased in MPV in group 3. This agreed with the findings of Bulur et al, 2012 who reported no significant changes in MPV in women on COC. Platelet size, measured as mean platelet volume (MPV) is a marker of platelet function and is associated with thrombotic risk.

In recent times $\mathrm{COC}$ with low estrogen content are being recommended to minimize the size effects. The COC pill used in this study, DUOFEM contains $0.03 \mathrm{mg}$ ethinylestradiol $0.0 \mathrm{mg}$ norgestrel.

\section{Conclusion}

We determined that using COC, DUOFEM for contraception may not change platelet count or mean platelet volume. Detail study of the action of this drug on platelet reactivity is hereby advocated.

\section{References}

[1] Ankara U, Gulseli Y, Aylin Y, Feride S (1996). Normal platelet count and the causes of low and high platelet count. Turkiye Klinkleri J. Gynecol Obst. 6:169-172.

[2] Bulur, S. Albayrak, M, Keskin F, Kose S.A., Aslantas Y, Turker Y, Ozhan, H. (2012). Effect of combined oral contraceptive use on platelet volume in women at reproductive age. Clin Exp Obstet Gynecol; 39(3): $314-316.1$

[3] Malley, T.O., Langhorne, P., Elton, R.A, Stewart, C. (1995). Platelet size in Stoke patients. Stoke; 26: 995 - 999.

[4] Martin, J.F, Trowbridge, A. eds. (1990). Platelet Heterogeneity: Biology and Psthology. London, UK: Springer-Verlage.

[5] Odlind V,Milson I, Person I, Victor A (2002). Can changes in sex hormone binding globulin predict the risk of venous thromboembolism with combined oral contraceptives pills? Acta Obset.Gyneco. Scand; 8(6):282-290.

[6] Beackkan, S.K., Methiesen, E.B. Njolstad, I. Willsgaard, T., Stormers, J., Hansen, B. (2010). Mean platelet volume is a risk factor for various thromboembolisms: The Tromso Study Journal of Thrombosis and Haemostasis, 8: 157 - 162.

[7] Sajida, S.H., Al-Chalaby, Sana'a M. Taib, Amjad, F. Ahmed (2006). Effect of oral contraceptive pills on haematological indices. Tikrit Medical Journal; 12(1): $65-69$.

[8] Inmam, W.H.W., Vassey, M.P., Westerholm, B., Engelind, A. (1970). Themoboembolic disease and the estradiol content of oral contraceptives. A report to the committee on safety of drugs; Br. Med. J. (2): $203-209$.

[9] David, J. Kuter (1996). The physiology of platelet production. STEM CELLS; 14(1): 88.

[10] Abdalla, T.M. Kardofani A.A.Y, Nimir A.A.H (2008) Khartoum Med. Journal; 1(3): $116-118$. 
[11]Babatunde, A.S. Olatunji, P.O. (2004). Short term effect of oral contraceptive pills on some haenmostatic parameters in healthy Nigerian women. Nig. Postgrad. Med. Journal; 4: $246-250$.

[12]Jack MA, Akinsete I, Onitiri AC (1988): Effects of oral contraceptives on serum lipoproteins, coagulation and fibrinolysis in Nigerian women. Nig. Med. Pract. ; 15: 14 - 18 Thakurdesai PA, Kole PL \& Pareek RP (2004), Evaluation of the quality and contents of diabetes mellitus patient education on Internet. Patient Education and Counseling 53, 309-313. 